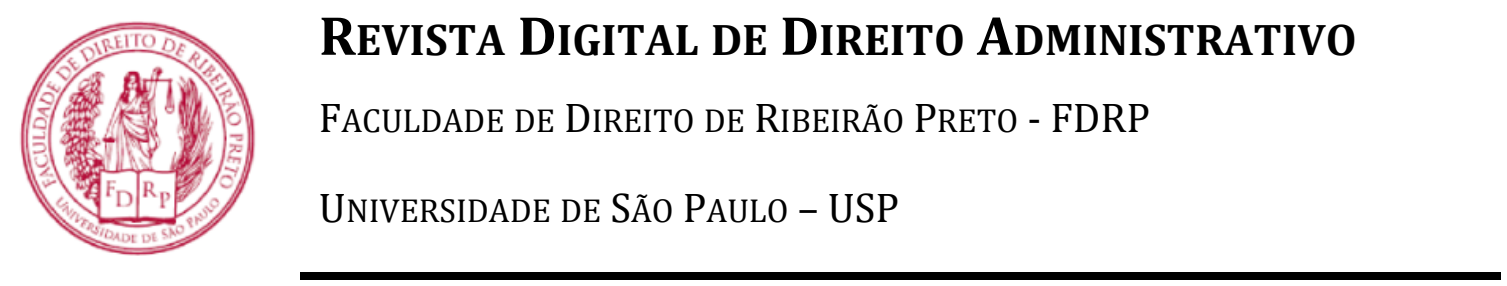

\title{
Seção: Artigos Científicos \\ As audiências de conciliação e mediação nos conflitos envolvendo a Fazenda Pública
}

The conciliation and mediation hearings in conflicts involving the public treasury

\author{
Adriane da Silva Garcel, Anderson Ricardo Fogaça, José Laurindo de Souza Netto
}

\begin{abstract}
Resumo: 0 presente artigo tem como finalidade abordar as novas diretrizes processuais e procedimentais elencadas no Código de Processo Civil de 2015, a fim de salvaguardar a efetiva solução do mérito da demanda sem lesar os princípios da celeridade e eficiência processual. Assim, pode-se citar o sistema multiportas, o qual inclui diversos instrumentos para solução de conflitos. Entre estes, estão a audiência de conciliação ou mediação, a ser realizada em momento anterior à apresentação da contestação, conforme art. 334 do CPC. Nessa perspectiva, a Fazenda Pública não foi repelida desse procedimento, apesar de seus interesses serem, via de regra, indisponíveis. Nesse sentido, "as Fazendas Públicas devem dar publicidade às hipóteses em que seus órgãos de Advocacia Pública estão autorizados a aceitar autocomposição". Entretanto, o legislador não elencou nenhuma especificidade para a audiência de conciliação ou mediação quando o ente público for sujeito processual. Nesse caso, frisa-se que, em decorrência do princípio da legalidade, o administrador público só poderá transacionar se houver previsão legislativa para tal. Contudo, conforme previsto no artigo 3으, § 3oㅡㄹ do CPC/2015, cabe aos advogados o estímulo aos meios de autocomposição, como também informar ao juízo caso sobrevenha alguma autorização para transação, como forma de obedecer ao artigo supracitado.
\end{abstract}

Palavras-chave: Novo Código de Processo Civil; Fazenda Pública; Audiência de Conciliação e Mediação.

Abstract: The purpose of this article is to address the new procedural and procedural guidelines listed in the 2015 Code of Civil Procedure in order to safeguard the effective settlement of the merits of the claim without undermining the principles of speed and procedural efficiency. Thus, we can mention the multiport system, which includes several tools for conflict resolution. Among these are the mediation and conciliation hearing to be held prior to the presentation of the defense, as per art. 334, of the CPC. From this perspective, the Public Treasury was not rejected from this procedure, although its interests are, as a rule, unavailable. In this sense, "Public Treasures should publicize the assumptions in which their Public Advocacy bodies are allowed to accept self-composition." However, the legislature did not list any specificity for the conciliation hearing when the public entity is a procedural subject. In this case, it is important to emphasize that, due to the principle of legality, the public administrator can only transact if there is legislative provision for this to occur. However, as provided for in Article 3, paragraph 3, of CPC / 2015, it is up to lawyers to encourage self-composition, as well as to inform the court in case any authorization to self-compose, as a way of obeying the aforementioned article.

Keywords: New Code of Civil Procedure; Public Treasury; Conciliation and Mediation Hearings.

Disponível no URL: www.revistas.usp.br/rdda

DOI: http://dx.doi.org/10.11606/issn.2319-0558.v7n2p252-268

Este conteúdo está protegido pela lei de direitos autorais. É permitida a reprodução, desde que indicada a fonte como "Conteúdo da Revista Digital de Direito Administrativo". A RDDA constitui periódico científico da FDRP/USP, cuja função é divulgar gratuitamente pesquisa na área de direito administrativo. Editor responsável: Professor Associado Thiago Marrara. 


\section{AS AUDIÊNCIAS DE CONCILIAÇÃO E MEDIAÇÃO NOS CONFLITOS ENVOL- VENDO A FAZENDA PÚBLICA}

Adriane da Silva GARCEL *, Anderson Ricardo FOGAÇA**, José Laurindo de SOUZA NETTO***

Sumário: 1 Introdução; 2 Audiências de conciliação e mediação à luz do Código de Processo Civil; 3 Os direitos tutelados pela Fazenda Pública; 4 As audiências do artigo 334 do Código de Processo Civil nos conflitos envolvendo a Fazenda Pública; 5 Conclusões; 6 Referências bibliográficas.

\section{Introdução}

Certo é que o legislador do Código de Processo Civil empregou grande esforço para instaurar um novo paradigma solucionador de conflitos na congestionada e ineficiente justiça brasileira, dando especial destaque aos mecanismos consensuais de resolução de conflitos e à construção de um modelo cooperativo de processo, elegendo como princípios norteadores desse novo ideário a i) colaboração dos sujeitos processuais e a ii) efetividade processual.

Com isso, uma série de dispositivos tratando de métodos socialmente adequados de resolução de conflitos - como a conciliação e a mediação - passaram a ser previstos ao longo do codex, como ensina Fernanda Tartuce (2013, p. 22):

Com efeito, desde que haja disposição dos envolvidos o tratamento consensual é sempre possível: ainda que escolhida inicialmente a via contenciosa, as partes podem, com base em sua autonomia, decidir buscar saídas conjuntas. (...). Na parte geral, além da previsão no início do Código ao abordar a inafastabilidade da jurisdição, há toda uma seção dedicada ao assunto entre os auxiliares da justiça. Há ainda capitulo dedicado à audiência de conciliação em que a mediação vem mencionada em dois parágrafos. Ao tratar da audiência de instrução e julgamento, prevê o Código que logo após sua instalação "o juiz tentará conciliar as partes, sem prejuízo de encaminhamento para outras formas adequadas de solução de conflitos, como a mediação, a arbitragem e a avaliação imparcial por terceiro". Mais adiante, a mediação é referenciada no livro de procedimentos especiais,

\footnotetext{
* Mestranda em Direito Empresarial e Cidadania no Centro Universitário de Curitiba - UNICURITIBA. Pós-graduada em Direito Aplicado pela Escola da Magistratura do Paraná - EMAP e Pós-graduada em Ministério Público - Estado Democrático de Direito pela Fundação Escola do Ministério Público - FEMPAR. Assessora jurídica do TJPR e Mediadora Judicial.

** Mestre em Direito pela Universidade Internacional - UNINTER. Professor da Escola da Magistratura do Paraná - EMAP e Juiz de Direito em Segundo Grau do Tribunal de Justiça do Estado do Paraná.

*** Pós-Doutor em Direito pela Faculdade de Direito da Universidade Degli Studi di Roma "La Sapienza". Doutor em Direito pela Universidade Federal do Paraná. Desembargador do Tribunal de Justiça do Estado do Paraná. 2o Vice-Presidente do Tribunal de Justiça do Estado do Paraná na Gestão 2019/2020.
} 
que passa, de forma inovadora, a destinar um capítulo ao processamento das demandas familiares. Merece ainda destaque pioneiro dispositivo sobre a criação de câmaras de conciliação e mediação para dirimir conflitos no âmbito administrativo. Com a inserção de dispositivos sobre mediação e a ampliação de previsões sobre a conciliação, dois modos diferentes de lidar com as controvérsias passam a conviver mais intensamente no Código de Processo Civil: a lógica de julgamento e a lógica coexistencial (conciliatória).

Dentre eles, o artigo 334 do Código de Processo Civil, de modo inovador, trouxe a obrigatoriedade de designação da audiência inicial de conciliação ou mediação após o recebimento da inicial, antes da polarização do litígio - concretizada pela resistência à pretensão pelo oferecimento da contestação —, prevendo, expressamente, dispensa nos casos em que o provimento se demonstrar inútil, seja diante da manifestação expressa de ambas as partes demonstrando desinteresse na composição, seja nos casos em que não é admitida transação, deixando evidente sua opção favorável à autocomposição.

Ainda, tamanho é o estímulo a esses métodos socialmente adequados de resolução de conflitos que o CPC, no $\S 8^{\text {o }}$ daquele dispositivo, prevê como ato atentatório à dignidade da justiça (sancionado com multa de até 2\% da vantagem econômica pretendida ou do valor da causa, revertida em favor da União ou do Estado), hipóteses em que a parte injustificadamente deixa de comparecer ao ato.

Observa-se que o CPC foi expresso ao dispensar a audiência prévia nos casos em que não for cabível autocomposição ( $\$ 4^{\circ} \stackrel{\circ}{*}$ inc. II), englobando a grande maioria dos processos contemporâneos, inclusive aqueles envolvendo a Fazenda Pública, embora se saiba que "nem todo direito indisponível implica a impossibilidade de haver transação que o envolva", conforme ressalta Fredie Didier Jr. (2010, p. 130131).

Destarte, a Fazenda Pública tem por finalidade precípua a garantia do bem comum da coletividade administrada, devendo observar, quando de sua atuação, os princípios da legalidade, supremacia do interesse público sobre o do particular e indisponibilidade do interesse público.

A indisponibilidade do interesse público, porém, não pode significar que todos os direitos tutelados pela Fazenda Pública sejam absolutamente indisponíveis. Para atender em maior medida aos interesses tutelados, a autocomposição será admitida, em determinadas situações e hipóteses, nas ações em que for parte a Fazenda.

De outra banda, conforme ressalta Ravi Peixoto (2016, p. 13), "o que parece ser o grande desafio não é a verificação da aptidão ou não dos entes públicos de fazer acordos, mas sim quais seriam as suas condições". Isto porque os conflitos que envolvem direito público possuem menor liberdade para negociações, mormente porque os procuradores não detêm autorização normativa para transacionar em au- 
diência - que, na maioria das vezes, sequer é realizada —, fato que, na prática, acaba implicando a inadmissão da autocomposição.

Desta forma, o presente estudo tem por objetivo tratar dos institutos da conciliação e mediação dispostos no artigo 334 do Código de Processo Civil dentro da seara dos conflitos que envolvem a Fazenda Pública, investigando se, diante dos princípios acima referenciados, a participação da Fazenda nessa audiência preliminar estaria excepcionada.

Para tanto, far-se-á uso do método lógico-dedutivo, tendo como fonte artigos, doutrinas e Códigos Comentados a respeito do tema, primeiramente tratando-se dos institutos da conciliação e mediação à luz do Código de Processo Civil; após, perpassando pelo tema dos direitos tutelados pela Fazenda Pública; e, por fim, adentrando a problemática tratada a respeito da aplicabilidade do artigo 334 do Código de Processo Civil aos conflitos envolvendo a Fazenda Pública.

\section{Audiências de conciliação e mediação à luz do Código de Processo}

\section{Civil}

O Código de Processo Civil de 2015 trouxe inúmeras inovações ao sistema processual que disciplina, e uma delas foi o sistema multiportas para a resolução de conflitos, podendo-se citar, como exemplos, a conciliação e a mediação, sendo que a utilização destes institutos torna a prestação jurisdicional mais efetiva.

De acordo com o caput do artigo 334 do Código de Processo Civil, o magistrado, ao constatar que a petição inicial cumpre os requisitos essenciais e não sendo o caso de improcedência liminar do pedido, designará a audiência de conciliação ou mediação, determinando a citação do réu para comparecer ao ato:

Art. 334. Se a petição inicial preencher os requisitos essenciais e não for o caso de improcedência liminar do pedido, o juiz designará audiência de conciliação ou de mediação com antecedência mínima de 30 (trinta) dias, devendo ser citado o réu com pelo menos 20 (vinte) dias de antecedência.

Para Marcus Vinícius Rios Gonçalves (2017, p. 172) a audiência de conciliação ou mediação é imprescindível nos processos que tramitam pelo procedimento comum, e sua definição, mesmo antes da apresentação da contestação, consiste na ideia de que, após proposta a peça de defesa pelo réu, o conflito poderá exacerbarse, tornando-se mais difícil a autocomposição entre as partes (então verdadeiramente) litigantes.

Com o objetivo de facilitar o estudo do Código de Processo Civil de 2015 no que concerne à conciliação e à mediação, inicialmente apresentam-se as diferenças entre os institutos citados, vez que não se confundem. 
O termo "conciliação" origina-se do latim conciliare, que consiste em atrair, ajudar, harmonizar. Cuida-se de um meio socialmente adequado de pacificação social no qual os indivíduos procuram reparar as desigualdades por meio de um conciliador (SALLES, 2007, p.23). Roberto Portugal Bacellar (2003, p. 175) explica que a "conciliação é o acordo de vontades, em que as pessoas fazem concessões mútuas a fim de solucionar o conflito".

Já Nassif (2005, p. 215) explica que a conciliação é “o procedimento irritual, oral e informal (...) com vistas a buscar uma solução da controvérsia (...) mediante a elaboração de um acordo que (...) substitui eventual medida cautelar ou sentença, faz coisa julgada imediata e adquire a qualidade de título executivo judicial”.

Nesse sentido, a conciliação é um meio de resolução de conflitos em que um terceiro imparcial (pois equidistante) instrui ativamente os indivíduos que, preferencialmente, já possuem um vínculo anterior para a celebração de um acordo, propondolhes a melhor maneira de aproximar seus interesses.

Isso posto, tem-se que "o conciliador tem atuação mais ativa no mérito da questão, facilitando, sugerindo soluções, orientando os interessados, até mesmo sobre enfoques jurídicos" (BACELLAR, 2003, p. 95). É essa a função que se extrai do $\S 2^{\circ}$ do art. 165 do Código de Processo Civil:

(...) um processo de reconstrução simbólica do conflito, no qual as partes têm a oportunidade de resolver suas diferenças reinterpretando, no simbólico, o conflito com o auxílio de um mediador, que as ajuda, com sua escuta, interpretação e mecanismos de transferência, para que elas encontrem os caminhos de resolução, sem que o mediador participe da resolução ou influencie em decisões ou mudanças de atitude (nisso se baseia sua imparcialidade; é imparcial porque não resolve nem decide).

Maria de Nazareth Serpa (1999, p. 90), descreve a mediação como um processo informal e voluntário, o qual exibe um terceiro interventor e imparcial que auxilia os disputantes na solução de seus litígios. Acresce que a função do interventor é auxiliar no diálogo por meio de negociação de acordos, neutralização de emoções e formação de opções. A autora relaciona a mediação como o agente fora do âmbito conflituoso, que atua como catalisador de disputas ao guiar as partes às suas elucidações, sem precisamente envolver-se na substância destas.

Desse modo, a mediação é elencada como um método de resolução de conflitos no qual "um terceiro, imparcial, dá assistência às pessoas em litígio com a finalidade de que possam manter uma comunicação produtiva à procura de um acordo possível para elas" (BAVARESCO, 2006, p. 14). 
Ademais, a mediação busca a pacificação dos conflitos, transferindo autonomia às partes que possuem voz ativa para esclarecer as contendas, buscando por elas próprias alternativas para pacificação do conflito.

Nessa perspectiva, aduz Medina (2004, p. 58-59) que:

A mediação busca, essencialmente, a aproximação das partes. 0 instituto da mediação não se preocupa unicamente com a obtenção de um simples acordo entre os indivíduos litigantes. 0 objetivo maior a ser alcançado é o reatamento entre aqueles que estavam em conflito. Pacificar relações, eis o fim máximo pretendido com a mediação.

É necessário frisar que o mediador, diferentemente do conciliador, atua preferencialmente nos casos em que houver vínculo anterior entre as partes. Nesta técnica, o mediador não pode propor a solução aos interessados, devendo, apenas, auxiliar na comunicação entre os envolvidos, facilitando o entendimento do caso e das opções, para que as partes identifiquem, por si só, soluções consensuais que gerem benefícios mútuos (DIDIER JR, 2015, p. 275):

Art. 165. (...)

$\S 3^{\circ} 0$ mediador, que atuará preferencialmente nos casos em que houver vínculo anterior entre as partes, auxiliará aos interessados a compreender as questões e os interesses em conflito, de modo que eles possam, pelo restabelecimento da comunicação, identificar, por si próprios, soluções consensuais que gerem benefícios mútuos.

Como brevemente mencionado, o CPC também elencou duas hipóteses nas quais a audiência prévia de conciliação ou mediação não será realizada, são elas: a) se ambas as partes manifestarem, expressamente, desinteresse na composição consensual (art. 334, § 4ํㅡㄹ inc. I); b) quando não se admitir a autocomposição (art. 334, § 4oㅡ, inc. II).

Ainda, Fernanda Tartuce (2016, p. 105-106) explica a relevância de dividir os institutos de conciliação e mediação para que não haja desordem quanto às técnicas empregadas e os objetivos de cada um:

[...] na mediação, o terceiro neutro "procura criar as condições necessárias para que as próprias partes encontrem a solução", não intervindo no sentido de adiantar alguma proposta de solução; na conciliação, o terceiro interfere um pouco mais ao tentar apaziguar as partes, podendo sugerir algumas soluções para o conflito.

Prossegue demonstrando que a diferença se refere à extensão da atuação do mediador e do conciliador no que concerne à formação da vontade das partes, uma vez que o mediador procura fazer com que os envolvidos elaborem propostas, enquanto o conciliador contribui para sua formulação, podendo até propor o conteúdo do acordo (TARTUCE, 2016, p. 106). 


\section{Os direitos tutelados pela Fazenda Pública}

Antes de se adentrar o cerne da questão, expor-se-ão algumas peculiaridades referentes à Fazenda Pública. Conforme ensina Hely Lopes Meirelles, "a Administração Pública, quando ingressa em juízo por qualquer de suas entidades estatais, por suas autarquias, por suas fundações públicas ou por seus órgãos que tenham capacidade processual, recebe a designação tradicional de Fazenda Pública, porque seu erário é que suporta os encargos patrimoniais da demanda" (MEIRELLES, 1998, p. 590).

Segundo José dos Santos Carvalho Filho (2009, p. 1044), trata-se, o emprego do termo, de mera praxe forense. Não obstante, os fins perseguidos pela Administração Pública em juízo continuam a ser os da garantia do bem comum da coletividade administrada e do interesse público enquanto norte do regime jurídico administrativo, aqui destacando-se os princípios da legalidade, supremacia do interesse público sobre o do particular e indisponibilidade do interesse público.

A respeito destes princípios norteadores do agir do administrador público, Matheus Carvalho (2015, p. 62) elucida:

Ademais, pode-se entender que o princípio da legalidade é corolário da regra de indisponibilidade do interesse público. Afinal, a lógica é que o administrador não pode atuar de forma a dispor do interesse público e, portanto, sua atuação fica dependendo da autorização do titular do interesse público (o povo), responsável pela elaboração das leis, por meio de seus representantes legitimamente escolhidos. Sem embargo, a autorização legal configura a manifestação da vontade popular no sentido de que é possível ao administrador praticar uma determinada conduta, sem que isso configure disposição dos direitos da coletividade.

Apesar das prerrogativas de que goza, a Administração Pública, enquanto guardiã do interesse público, deverá atuar dentro dos limites do referido interesse, não podendo dele se afastar ou desviar, interesse este que deverá estar acima dos interesses particulares. Por isso, diz-se que "a Administração Pública não é titular do interesse público, mas apenas a sua guardiã, na medida em que a ela incumbe apenas cuidar de sua proteção" (DI PIETRO, 1991, p. 163). Igualmente, o princípio da legalidade, disposto no artigo 37 da Constituição Federal, também deve ser tido como norte condicionante do agir da Administração Pública, que ficará condicionada àquilo que estiver elencado na lei em sentido amplo.

Nesse sentido, Charles Eisemann (2020, p. 69-70) esclarece que:

Se se entende o princípio da legalidade como de não-contrariedade ou compatibilidade, ele constitui certamente a regra mais geral do direito administrativo, mas não, nem ele mesmo, regra absoluta; ele não é esse princípio infringível, este dogma soberano e sacrossanto 
como o queriam as proposições da teoria ortodoxa de nosso direito público. Politicamente felizes ou politicamente lamentáveis, o juiz dá origem a um certo número de atentados de princípio à essa lei da qual é oficial e juridicamente o guardião inflexível, o mantenedor inexorável. Afastando a lei, corrigindo-a, faz então o direito, torna a fazê-lo. Isenta a Administração da sua obrigação de obediência, eximindo-se a si próprio da sua.

Contudo, como adiantado, ao se falar em indisponibilidade do interesse público, não se quer dizer que todos os direitos tutelados pela Fazenda Pública são absolutamente indisponíveis; pelo contrário, para fins de atender em maior medida os interesses tutelados pelo Estado, em determinadas situações e hipóteses a autocomposição será admitida.

Não obstante, os direitos tutelados pela Fazenda podem ancorar-se tanto em interesse público primário como em interesse público secundário, estes últimos transacionáveis, porquanto relacionados aos interesses privados dos Estados (MARINONI,2008, p. 326). É a hipótese dos contratos administrativos celebrados pelos entes com particulares de natureza privada, "em que não se faz presente a superioridade do Poder Público frente ao particular (contratos da administração)" (CAVALCANTE, 2012, p. 56).

A Fazenda Pública é representada por meio de seus Procuradores, servidores que tem por atribuição defesa processual do interesse material do Estado (CASADO, 2018, p. 101). Veja-se que a independência funcional dos procuradores se restringe à escolha da estratégia defensiva que melhor atinja e resguarde o interesse público, por isso fala-se em defesa processual. Contudo, isso não se estende ao mérito da matéria posta em juízo, na medida em que não cabe ao procurador adentrar as questões materiais das escolhas feitas pela Administração, muito menos se fazer substituir ao administrador na tomada daquelas decisões que eventualmente foram judicializadas.

Destarte, aqui se instaura verdadeira celeuma. Considerando a indisponibilidade do interesse público, o princípio da legalidade e a atribuição dos procuradores, como fica a obrigatoriedade da audiência prévia de conciliação disposta no artigo 334 do CPC? Quais seriam as condições dos acordos realizados pelos entes públi$\cos$ ?

\section{As audiências do artigo 334 do Código de Processo Civil nos confli- tos envolvendo a Fazenda Pública}

Conforme já abordado, o Código de Processo Civil tem por intuito fomentar, em máxima medida, a adoção de um sistema multiportas, fazendo frente a uma justiça ineficiente e atrasada que distribui mal o ônus do tempo do processo. 
Uma das hipóteses de dispensa da audiência prévia de conciliação ou mediação é a inadmissão da autocomposição. Poder-se-ia, a partir dessa proibição, sustentar a inaplicabilidade do art. 334 do CPC à Fazenda Pública, mas, como explica Fredie Didier Jr. (2016, p. 273), a inadmissibilidade da autocomposição não é consequência necessária da indisponibilidade do interesse público pela Administração Pública:

Não se pode confundir "não admitir autocomposição", situação que autoriza a dispensa da audiência, em ser "indisponível o direito litigioso". Em muitos casos, o direito litigioso é indisponível, mas é possível haver autocomposição. Em ação de alimentos, é possível haver o reconhecimento da procedência do pedido pelo réu e acordo quanto ao valor e forma de pagamento; em processos coletivos, em que o direito litigioso também é indisponível, é possível celebrar compromisso de ajustamento de conduta (art. 5으, § 5o, Lei n. 7.247/1985). Na verdade, é rara a hipótese em que se veda peremptoriamente a autocomposição. O Poder Público, por exemplo, somente pode resolver o conflito por autocomposição quando houver autorização normativa para isso - fora dessas hipóteses, não há como realizar a autocomposição. Nesses casos, o réu será citado para apresentar resposta, no prazo legal, sem a intimação para comparecer à audiência, que não se realizará (art. 335, III, CPC). Isso não quer dizer que não há possibilidade de autocomposição nos processos de que faça parte ente público. Há, ao contrário, forte tendência legislativa no sentido de permitir a solução consensual dos conflitos envolvendo entes públicos. A criação de câmaras administrativas de conciliação e mediação é um claro indicativo nesse sentido (art. 174, CPC). Cada ente federado disciplinará, por lei própria, a forma e os limites da autocomposição de que façam parte.

Nessa toada, verifica-se que a indisponibilidade do interesse público não se confunde com a impossibilidade de autocomposição. Nas ações envolvendo pessoas jurídicas de direito público, é possível a celebração de acordo em sede de audiência preliminar de conciliação ou mediação, em certas situações, "tais como a forma de efetivação de determinada decisão judicial e as hipóteses em que o acordo melhor atenda ao interesse do Estado" (FERREIRA, 2017, p. 89).

A verdade é que nem todo direito indisponível implica a impossibilidade de haver transação que o envolva. Reforçando esse entendimento, Rinaldo Mouzalas, Terceiro Neto e Madruga (2016) salientam que "afasta-se a clássica confusão de que todo direito indisponível não admite autocomposição". Além disso, "transigir não significa, necessariamente, abrir mão do interesse público, mas, em determinadas hipóteses, buscá-lo de forma mais eficiente, proporcional e razoável, não havendo nenhuma incompatibilidade, em princípio, entre ambos" (DIDIER JR, 2016, p. 273). 
Aliás, havendo autorização legal e mostrando-se a autocomposição mais adequada à persecução do interesse público, deverá ser designada a audiência prévia. Se o próprio legislador empregou esforços para a materialização da adoção dos meios socialmente adequados de resolução de conflitos, não há razão para que essa prática não seja fomentada e aplicada.

Contudo, há que se repisar a necessidade de autorização normativa para que os procuradores possam transacionar em audiência, diante dos limites impostos pelo princípio da legalidade (art. 37 da CF). Ademais, serão excepcionais as ocasiões em que se impede, de forma absoluta, a autocomposição, sendo, quanto àquele (direito indisponível), possível a transação.

Ravi Peixoto (2016, p. 45) bem enfrenta o tema:

(...) [a] necessidade de autorização normativa para a autocomposição pelos entes públicos decorre do princípio da legalidade (artigo 37, CF), que, em relação ao poder público, tem como uma de suas decorrências a exigência de que este só pode atuar na medida do que é autorizado por algum texto normativo. Essa autorização pode decorrer tanto diretamente da lei como ser feita por meio de ato normativo do chefe do Poder Executivo regulamentando o exercício da autocomposição pelo poder público.

Ainda, conforme o Enunciado de n⿳0 33 do II Fórum Nacional do Poder Público, "a audiência de conciliação do art. 334 somente é cabível para a Fazenda Pública se houver autorização específica para os advogados públicos realizarem acordos". Assim, é indispensável que o Poder Judiciário identifique hipóteses em que será admissível e fundamental a realização da audiência de conciliação ou mediação prevista no art. 334 do CPC quando o Poder Público estiver em juízo.

Importante mencionar que, à luz do novo paradigma processual civil da cooperação, o Enunciado no 16 do I Fórum Nacional do Poder Público orienta que "a Administração Pública deve publicizar as hipóteses em que está autorizada a transacionar". Este enunciado, assim como o anteriormente citado, busca encontrar uma solução no que se refere à tensão entre a tutela dos interesses públicos por parte da Fazenda Pública e sua indisponibilidade e a obrigatoriedade de sua participação na audiência do art. 334 do CPC.

Superado o impasse acerca do cabimento da audiência prévia de conciliação nos conflitos envolvendo a Fazenda, resta tratar acerca das hipóteses de dispensa.

Conforme ressalta Ravi Peixoto (2016, p. 102), “o que parece ser o grande desafio não é a verificação da aptidão ou não dos entes públicos de fazer acordos, mas sim quais seriam as suas condições". Isto porque, além da pequena liberalidade que tem os procuradores de transacionar, diante dos interesses em jogo, muitas vezes a necessária autorização legislativa sequer existe, o que, na prática, acaba implican- 
do a inadmissão da autocomposição. Neste contexto, seria o caso de não designação da aludida audiência?

Como dito, havendo autorização normativa - respeitado, assim, o princípio da legalidade - a audiência do artigo 334 do CPC deverá ser mantida. Do contrário, inexistindo expressa previsão legal neste sentido, a audiência não deverá ser marcada, porquanto estar-se-á diante da hipótese do inciso II do $§ 4^{\circ}$ do artigo 334 do CPC, que trata da inadmissão da autocomposição.

Neste caso, estando o atuar do procurador adstrito ao princípio da legalidade e não havendo norma autorizando a autocomposição, não haveria como ser lançada proposta de acordo, mostrando-se inútil o provimento que deveria ser dispensado em respeito à própria efetividade processual que o dispositivo visa a proteger:

O Poder Público somente pode resolver o conflito por autocomposição quando houver autorização normativa para isso - fora dessas hipóteses, não há como realizar autocomposição (ART. 334 CPC). Mas há um claro estímulo a essa forma de solução de conflito pelo Poder Público - os art. 32-40 da Lei n. 13.140/2015 são inteiramente dedicados a isso. Nesses casos, o réu será citado para apresentar resposta, no prazo legal, sem a intimação para comparecer à audiência, que não se realizará (art. 335, III, CPC) (DIDIER JR., 2016, p. 273).

Destarte, verifica-se que a interpretação do art. 334 do CPC pura e simples não pode ser adotada de maneira absoluta. É certo que não deverá o magistrado presumir impossível a autocomposição e, como regra, dispensar a audiência apenas por envolver a Fazenda Pública - o que iria de encontro aos pilares multiportas do próprio Código de Processo Civil.

Neste contexto, a Lei no 8.666/1993, em seus artigos 65 e 79, autoriza a realização de acordo nos contratos administrativos. Também, o artigo 86 da Lei no 12 . 529/2011 trata da possibilidade de composição nos procedimentos sancionatórios do Cade e o $\S^{0}{ }^{\circ}$ do artigo 5ํ da Lei 7.347/1985 admite seja tomado compromisso de ajustamento de conduta em processos coletivos.

Além disso, os artigos 10 e 8o das Leis 10.259/2001 e Lei 12.153/2009, respectivamente, autorizam genericamente a transação por membro da advocacia pública e artigos $1^{\circ}$ e $2^{\circ}$, da Lei 9.469/1997, possibilitam que o Advogado-Geral da União, diretamente ou mediante delegação, e dirigentes máximos das empresas públicas, em conjunto com o dirigente estatutário da área afeta ao assunto possam autorizar acordos ou transações para prevenir ou terminar litígios.

Ainda, o artigo 3ํ da Lei 13.140/15 viabiliza composição no caso dos direitos indisponíveis que admitam transação, contudo acaba misturando os conceitos de indisponibilidade, autocomposição e transação, exigindo a homologação judicial e oitiva 
do Ministério Público nos casos envolvendo direitos indisponíveis. Ademais, o art. 32 da mesma lei autoriza a criação de Câmaras de Prevenção e Resolução Administrativa de Conflitos no âmbito da Advocacia Pública.

A Lei no 13.655/18, que promoveu mudanças na Lei de Introdução às Normas do Direito Brasileiro (LINDB), também inovou ao trazer, no artigo 26, autorização genérica para celebração de compromisso com o fito de eliminar irregularidade, incerteza jurídica ou situação contenciosa na aplicação do direito público, tendo sido de grade utilidade ao viabilizar, por exemplo, os Termos de Ajuste de Conduta, que vêm solucionando diversos litígios no Judiciário, além de prever a possibilidade de que o Ajuste de Conduta se estenda às esferas do Executivo e Legislativo. Ademais, ao longo do $\S 1^{\mathrm{o}}$ do artigo 26 , impõe certas limitações ao termo, ainda que abstratas.

A Lei 10.201/2020 foi outro importante passo no incentivo à consensualidade no âmbito da administração pública ao autorizar, por exemplo, que a AGU celebre acordos de até R \$ 50 (cinquenta) milhões, dispensado o aval do Executivo Federal, o que diminui a burocracia, confere mais autonomia e celeridade aos advogados públicos quando das tratativas para celebração de acordo. Além disso, o Decreto majora o limite do parcelamento para quitação do valor acordado para sessenta parcelas.

Somado a isso, a Portaria PGU 02/2014, traz novas regras referentes ao tema, como é o caso da quitação de no mínimo $30 \%$ do valor acordado para liberação dos bens judicialmente bloqueados ou conscritos. Também, a Portaria AGU 109/07, em seu art. 3ㅜㅡ, incisos I e II, autoriza transação no caso de erro administrativo reconhecido pela autoridade competente, ou advogado, por intermédio da simples análise das provas e documentos que instruem o processo, mediante motivação adequada e nos casos em que inexista controvérsia quanto a fato e direito aplicados.

De outra banda, havendo direito propriamente indisponível, ou inexistindo autorização normativa para autocomposição, o procedimento conciliatório prévio deverá ser dispensado. É nesse mesmo sentido que o Tribunal Regional Federal da 4a Região já se posicionou, afirmando não haver nulidade processual quando a audiência do art. 334 não é realizada por ser o direito público indisponível em razão da ausência de autorização para transacionar:

OBRIGAÇÃO DE NÃO FAZER. AGEFIS. LITISPENDÊNCIA. PRELIMINAR. AUSÊNCIA DE AUDIÊNCIA DE CONCILIAÇÃO. NULIDADE. IMPUGNAÇAÕ AO VALOR DA CAUSA. DEMOLIÇÃO. ÁREA PÚBLICA. PARCELAMENTO IRREGULAR. NÚCLEO RURAL CASA GRANDE. [...] II - A ausência da audiência de conciliação não gera nulidade do processo quando se trata de direito público indisponível. [...] (Acórdão n. 1132410, 20160110909597APC, Relator: VERA ANDRIGHI 6 MA CÍVEL, Data de Julgamento: 17/10/2018, Publicado no DJE: 30/10/2018. Pág.: 416/454). 
Em mesmo sentido, o Tribunal de Justiça do Estado de São Paulo compreende ser indispensável haver autorização legal para que a Fazenda possa transacionar, confira:

PROCESSUAL CIVIL - EMBARGOS À EXECUÇÃO CONTRA A FAZENDA PÚBLICA - SENTENÇA TRANSITADA EM JULGADO - TRANSAÇÃO - AUSÊNCIA DE AUTORIZAÇÃO LEGAL - INADIMISSIBILIDADE. Os bens públicos são indisponíveis e a Administração regida pelo princípio da legalidade (art. 37 CF). Para que a Fazenda Pública possa transacionar sobre obrigação fixada por sentença transitada em julgado é indispensável a existência de autorização legal, inexistindo na espécie. Precedente do STJ, Homologação de acordo recusada. Decisão mantida. Recurso desprovido. (TJ-SP - AI: 2215646- 76. 2016. 8. 26. 0000, Relator: Décio Notarangeli, Data de Julgamento: 22/02/2017, 9ạ Câmara de Direito Público, Data de Publicação: 23/02/2017).

Igualmente, o Tribunal de Justiça da Bahia:

ADMNISTRATIVO E PROCESSUAL CIVIL REEXAME NECESSÁRIO. AÇÃO DE COBRANÇA. MUNICÍPIO DE ITABUNA. SENTENÇA HOMOLOGATÓRIA DE TRANSAÇÃO ENTRE A FAZENDA PÚBLICA E PARTICULAR. IMPRESCINDIBILIDADE DE SUBMISSÃO AO DUPLO GRAU DE JURISDIÇÃO. AUSÊNCIA DE TRÊNSITO EM JULGADO DA DECISÃO. SÚMULA 423, DO STF. COMPROVAÇÃO DE LEI MUNICIPAL PERMISSIVA DA TRANSAÇÃO. TRANSAÇÃO BENÉFICA À FAZENDA PÚBLICA MUNICIPAL. CLÁUSULA PREVENDO A FORMA DE PAGAMENTO QUE NÃO VIOLA O REGIME DE PRECATÓRIOS. VALIDADE DA TRANSAÇÃO REALIZADA. (TJ-BA- Remessa Necessária: 0523358120148050113, Relator: Maurício Kertzman Szporer, Segunda Câmara Cível, Data de Publicação: 01/02/2017).

Não obstante, a simples ausência de indicação na inicial de interesse na audiência de conciliação ou mediação por si só não acarreta sua dispensa, conforme decidido pela 3a Câmara do Tribunal de Justiça de Goiás ao julgar os autos de Apelação no 0203953.51.2016.8.09.0082, lógica idêntica à adotada nos processos que não envolvem a Fazenda Pública.

Nesse contexto, Ravi Peixoto (2016) destaca a necessidade de que haja a realização de protocolos institucionais entre os entes públicos e o Judiciário informando em quais casos restaria ou não possível a autocomposição, evitando discussões sobre o cabimento da audiência. Outra solução apontada pelo autor seria dispensar, já no despacho inicial, a audiência daqueles processos que, diante do notório conhecimento, já é sabido que aqueles direitos não são transacionáveis (RAVI, 2016, p. 99). 
Por fim, caberia à própria Fazenda "dar publicidade às hipóteses em que seus órgãos de Advocacia Pública estão autorizados a aceitar autocomposição", nos moldes do Enunciado 573 do Fórum Permanente de Processualistas Civis.

Verifica-se, portanto, que a simples presença do Poder Público em juízo não é satisfatória para banir a imposição de realização da audiência de conciliação ou mediação elencada no art. 334 do Código de Processo Civil 2015. Todavia, um instrumento normativo legal, dada a adequada publicidade, seria apto, ao que tudo indica, a resolver tal discussão a respeito da participação da Fazenda Pública no procedimento de conciliação ou mediação.

\section{Conclusão}

A audiência de conciliação ou mediação desempenha papel essencial para a evolução no sistema processual brasileiro, especialmente diante do novo sistema multiportas que o Código de Processo Civil visa a implementar.

À vista disso, o legislador designou, no art. 334 do CPC, de forma obrigatória, a realização da audiência prévia de conciliação ou mediação, que apenas não será concretizada em duas hipóteses expressamente previstas no dispositivo legal, isto é, i) se ambas as partes manifestarem seu desinteresse na autocomposição ou ii) se o direito discutido nos autos assim não admitir.

Nos conflitos envolvendo o Poder Público, demonstrou-se que mesmo diante de suas peculiaridades e da indisponibilidade dos interesses e direitos tutelados, a audiência prévia do art. 334 do CPC deve ser concretizada desde que presente norma autorizadora, em observância ao princípio da legalidade. Portanto, quando a Fazenda Pública for parte da demanda, a audiência de conciliação e mediação, prevista no art. 334 do Código de Processo Civil, não deve ser, a priori, dispensada, devendo o magistrado realizar análise casuística.

Por outro lado, ausente norma autorizadora, estar-se-ia diante da hipótese elencada no inciso II do $\S 4^{\circ}$ do aludido dispositivo legal, devendo ser dispensada a realização da audiência em sede do próprio despacho inicial, privilegiando-se a efetividade processual, na medida em que, em não sendo admitida a autocomposição neste caso, a realização do ato se mostraria inútil.

Outra saída, por Ravi Peixoto, seria a realização dos chamados protocolos institucionais entre os entes públicos e o Judiciário, informando em quais casos a autocomposição seria viável. Além disso, o autor cita a possibilidade de dispensa da audiência, também por oportunidade do despacho inicial, nos casos em que há notório conhecimento acerca da impossibilidade de transação dos direitos envolvidos.

Por fim, cabe à própria Fazenda "dar publicidade às hipóteses em que seus órgãos de Advocacia Pública estão autorizados a aceitar autocomposição", nos moldes do Enunciado 573, do FPPC. 
Assim, fica evidente que não são em todas as situações a probabilidade de autocomposição dos direitos tutelados pela Fazenda Pública, contudo, é indispensável a análise individualizada de cada caso pelo magistrado, quem não poderá, apenas com fundamento em tratar-se de litígio envolvendo a Fazenda Pública, dispensar a audiência prévia, o que iria contra o próprio Código que tem por intuito o fomento da adoção dos métodos socialmente adequados de resolução de conflitos.

No entanto, compete ao ente político deliberar em instrumento normativo as hipóteses em que cabível à audiência para que o próprio Poder Judiciário apure a desnecessidade da realização da audiência do art. 334 do CPC.

\section{Referências bibliográficas}

BACELLAR, Roberto Portugal. Juizados Especiais - A nova mediação paraprocessual. São Paulo: Revista dos Tribunais, 2003. p. 175.

BAVARESCO, André Serra. Mediação: uma alternativa à jurisdição?. Porto Alegre, 2006, p. 14. Disponível em: https://www.lume.ufrgs.br/bitstream/handle/10183/13178/000582339.pdf?sequence=1. Acesso em 14 dez. 2019.

BRASIL. TRIBUNAL DE JUSTIÇA DO DISTRITO FEDERAL E TERRITÓRIOS. Apelação Cível no $\quad$ 20160110909597APC (0032105-48.2016.8.07.0018). 6 ${ }^{\mathrm{a}}$ Turma Cível. Relatora: Desembargadora VERA ANDRIGHI. Apelante (s): ALEX RAMOS DA ROCHA E OUTROS. Apelado(s): AGEFIS - AGÊNCIA DE FISCALIZAÇÃO DO DISTRITO FEDERAL. Publicado no DJE: 30/10/2018. p. 416454. Disponível em: https://tj-df.jusbrasil.com.br/jurisprudencia/643661305/20160110909597-df-0032105-4820168070018. Acesso em: 12 jul. 2020.

. TRIBUNAL DE JUSTIÇA DO ESTADO DE SÃO PAULO. Agravo de Instrumento no 2215646- 76. 2016. 8. 26. 0000. 9a Câmara de Direito Público. Relator: Desembargador DÉCIO NOTARANGELI. Publicado no DJE: 23/02/2017. Disponível em: https://tj-sp.jusbr asil.com.br/jurisprudencia/340757389/agravo-de-instrumento-ai-20560 817620168260000-sp-2056081-7620168260000. Acesso em: 9 jul. 2020.

TRIBUNAL DE JUSTIÇA DO ESTADO DA BAHIA. Remessa Necessária: 0523358120148050113. 2ª Câmara Cível. Relator: MAURÍCIO KERTZMAN SZPORER. Publicado no DJE: 1/02/2017. Disponível em: https://tj-ba.jusbrasil.com.br/jurisprudencia/348872178/remessa-necessaria3053357120148050146/inteiro-teor-348872189. Acesso em: 9 jul. 2020. . TRIBUNAL DE JUSTIÇA DE GOIÁIS. Apelação: 0203953.51.2016.8.09.0082. 3a Câmara Cível. Relator: ITAMAR DE LIMA. Publicado no DJE: 2 ago. 2019. Disponível em: https://tj-go.jusbrasil.com.br/jurisprudencia/740057798/apelacao-apl-2039535120168090082/inteiro-teor-740057800?ref=juris-tabs. Acesso em: 9 jul. 2020. 
CARVALHO FILHO, José dos Santos. Manual de Direito Administrativo. 22. ed. Rio de Janeiro: Lumen Juris, 2009.

CARVALHO, MATHEUS. Manual de Direito Administrativo. 2. ed. rev. e atual. Salvador: Editora Juspodivm.

CASADO, Ubirajara. A Fazenda Pública é obrigada a participar da audiência de conciliação prévia (art. 334, CPC/2015)?. Disponível em: https://blog.ebeji.com.br/a-fazenda-publica-e-obrigada-a-participar-de-audiencia-de-conciliacao-previa-art-334-cpc-15/. Acesso em: 12 dez. 2019.

CAVALCANTE, Márcio André Lopes. Revelia e fazenda pública. Buscador Dizer o Direito, Manaus. Disponível em: https://www.buscadordizerodireito.com.br/jurisprudencia/detalhes/7f16109f1619fd7a733daf5a84c708c1. Acesso em: 12 dez.2019.

DI PIETRO, Maria Sylvia Zanella. Discricionariedade administrativa na Constituição de 1988. São Paulo: Atlas, 1991.p. 163.

DIDIER JR., Fredie. Curso de Direito Processual Civil. 17. ed. Salvador: Juspodivm, 2015, v. 1, p. 625.

EISEMANN, Charles. O Direito Administrativo e o princípio da legalidade. Fundação Getúlio Vargas. Biblioteca digital. Disponível em: http://bibliotecadigital.fgv.br/ojs/index.php/rda/article/view/19443. Acesso em: 09 jul. 2020.

FERREIRA, Eduardo Henrique. A audiência de conciliação no Novo Código de Processo Civil e a Fazenda Pública. Conteúdo Jurídico, 2017. Disponível em: https://conteudojuridico.com.br/consulta/Artigos/50310/a-audiencia-de-conciliacao-no-novo-codigo-de-processo-civil-e-a-fazenda-publica. Acesso em: 16 dez. 2019.

GONÇALVES, Marcus Vinícius Rios. Novo Curso de Direito Processual Civil. 14. ed. São Paulo: Saraiva, 2017.

MARINONI, Luiz Guilherme, MITIDIERO, Daniel. Código de Processo Civil comentado artigo por artigo. São Paulo: RT, 2008.

MEIRELLES, Hely Lopes. Direito administrativo brasileiro. 23. ed. atual. São Paulo: Malheiros, 1998.

MOUZALAS, Rinaldo; TERCEIRO NETO, João Otávio; MADRUGA, Eduardo, Processo civil volume único. 8. ed. rev. e atual. Salvador: Ed. JusPodivm, 2016.

RAVI, Peixoto. A Fazenda Pública e a audiência de conciliação no novo CPC. Disponível em: http://www.conjur.com.br/2016-abr-07/ravi-peixoto-fazenda-audienciaconciliacao-cpc. Acesso em: 12 dez. 2019.

SALES, Lília Maia de Morais. Mediação de Conflitos: Família, Escola e Comunidade. Florianópolis: Conceito Editorial, 2007. 
SERPA, Maria de Nazareth. Teoria e Prática da Mediação de conflitos. Rio de Janeiro: Lumen Juris, 1999.

SOUZA, Luciane Moessa de. Meios consensuais de solução de conflitos envolvendo entes públicos e a mediação de conflitos coletivos. Tese de Doutorado. Florianópolis: UFSC, 2010, p. 130-131.

TARTUCE, Fernanda. Mediação nos Conflitos Civis. 2. ed. rev. e atual. São Paulo: Método. 2016. 